\title{
Effects of face-to-face counselling on unemployment rate and duration: evidence from a Public Employment Service reform
}

\author{
Ville Vehkasalo* (1)
}

\begin{abstract}
In a Public Employment Service reform implemented in 2013, sixty Finnish municipalities experienced an involuntary employment office closure. The Government's objective was to replace traditional face-to-face employment counselling with modern online counselling and simultaneously generate savings in outlays. The reform created natural experiment circumstances that allowed us to estimate the aggregate causal effects of face-to-face counselling and advice. We estimated the effects of the reform on the unemployment rate and the average unemployment duration using municipality-level panel data and various panel data estimators. We found that while the reform had a barely discernible effect on municipal unemployment rates, it increased average unemployment durations by $2-3$ weeks. Hence, face-to-face counselling and online counselling are not perfect substitutes in decreasing the length of unemployment spells. Consequently, the fiscal costs of the reform outweigh the fiscal benefits by a large margin.
\end{abstract}

Keywords: Counselling, Reform, Unemployment, Microdata

JEL Classification: J64, H76, C23

\section{Introduction}

In a time span of little more than two decades, the Internet has profoundly changed the way we buy clothes, book flights, make hotel reservations, and pay our bills, at least in the developed countries. Queuing at the bank is no longer necessary, and consequently, many bank branches have closed their doors. But not all markets are alike. As pointed out by Kuhn and Mansour (2014), "studies of the Internet's effects on labour market matching have been few in number and, on balance, find little or no evidence of a friction-reducing effect." This seems surprising: as communication costs have declined dramatically and online search has become a part of our everyday lives, we should in theory also see an increase in successful matches between jobseekers and vacancies. More efficient online job search would then decrease the need for traditional face-to-face counselling by the Public

*Correspondence: ville.vehkasalo@vtv.fi

National Audit Office of Finland, PO Box 1119, 00101 Helsinki, Finland
Employment Services, creating potential cost savings for the Government.

However, the labour market is in many ways different from the other markets. It may well be that personal communication and face-to-face counselling about labour market legislation, rules, and conventions are often needed, especially by newcomers. Nevertheless, regarding the causal effects of counselling and the effects of online job search, the empirical evidence is far from clear-cut on both counts.

In the meta-analysis of Whiston et al. (2003), the importance of counsellor ${ }^{1}$ involvement in career interventions received substantial support. Their results indicate that counsellor-free interventions are not as effective as other career treatment modalities and that effective career interventions need to include a counselling component (Whiston et al. 2003, 406). According to

\footnotetext{
${ }^{1}$ In Finnish, their title is työvoimaneuvoja (employment counsellor); in some countries, they are called caseworkers. Irrespective of the title, these professionals give advice, distribute job openings, and suggest training courses and other interventions for unemployed jobseekers.
} 
Brown and Roche $(2016,27)$, there is consistent metaanalytic evidence that career interventions, irrespective of modality, are demonstrably effective when compared to no-treatment or delayed-treatment controls. Intensive counselling schemes were found effective in reducing unemployment duration and recurrence in a duration analysis by Crépon et al. (2005).

On the other hand, Breunig et al. (2003) found out in a randomised trial that intensive counselling of the longterm unemployed was not effective in increasing employment. Van den Berg and Van der Klaauw (2006) also used data from a randomised trial and concluded that counselling and monitoring of unemployment insurance recipients did not affect their exit rate to work. In their study, the counselling meetings were implemented immediately at the beginning of an unemployment spell.

More recently, the counselling style, productivity, and cooperativeness of employment counsellors have been studied in counterfactual settings. Exploiting detailed Swiss data sets, Behncke et al. (2010a) found that the chance of re-employment increases if the counsellor and his client belong to the same social group. Behncke et al. (2010b), and later Huber et al. (2017) showed that "tough" caseworkers, who are less cooperative, are able to produce better employment results. Schiprowski (2017) used unplanned caseworker absences to investigate the effect of caseworker meetings. She found that missing one appointment increases the unemployment spell length by 10 days on average. The effect doubles if the caseworker belongs to the highest productivity tercile.

Stevenson (2008) concluded that increasing Internet penetration has increased the variety of job search methods and that job search behaviour has become more extensive. She also speculated that the Internet's ability to reduce the cost of on-the-job search may have changed the likelihood that a worker ends up unemployed. Kuhn and Mansour (2014), using longitudinal youth survey data, found positive effects for Internet job search. According to their estimates, using the Internet reduced individual unemployment durations on average by $25 \%$. This is in contrast with an earlier study by Kuhn and Skuterud (2004), which found that Internet job search was associated with longer unemployment durations in 1998-2000, most likely due to adverse selection of the searchers.

In a recent study, Kroft and Pope (2014) found no evidence that the rapid expansion of online service Craigslist as a job search tool has affected city-level unemployment rates. They used changes in city-level Craigslist job postings as an independent variable and used various OLS and IV regression specifications to estimate the effect on changes in the city-level unemployment rates. However, there are unresolved endogeneity issues in Kroft and Pope (2014) arising from their use of lagged dependent variables as confounders in their panel data models. ${ }^{2}$ Likewise changes in city populations-another confounder-could depend on changing unemployment levels, i.e. the dependent variable.

Hence, earlier studies have found contradictory evidence for the effectiveness of personal counselling and Internet job search. The aim of this study is to estimate the aggregate effects of face-to-face counselling on unemployment rate and duration. Our research agenda is based on a Public Employment Service (PES) office reform implemented in Finland at the beginning of the year 2013. In the reform, over 60 Finnish municipalities experienced an involuntary employment office closure. Employment office clients in the affected municipalities, having no choice in the matter, were forced to use the Internet, unless they were willing to travel to the nearest municipality with an existing employment office. To our best knowledge, this is the first study to estimate the aggregate effects of PES office closures. A related earlier research is Schiprowski (2017), which estimated the effect of missing a counselling appointment.

Specifically, we measure the municipality-level unemployment effects of dispensing with face-to-face counselling and replacing it with online and telephone counselling. In essence, we ask whether it is possible to substitute traditional employment counselling with modern online counselling and achieve cost savings at the same time. Using municipality-level unemployment data and various panel data estimators, we find that while the reform did not have a large effect on unemployment rates, it increased average unemployment durations by 2-3 weeks. Our estimate is robust to various sensitivity checks. We also find that the effect depends positively on the driving times from the affected municipalities to the nearest municipality with an available PES office. Therefore, our results suggest that online counselling and faceto-face counselling are not perfect substitutes.

\section{Research agenda}

In Finland, the Public Employment and Business Services, ${ }^{3}$ working under the Ministry of Economic Affairs and Employment, offer various re-employment and recruitment services for unemployed or employed jobseekers and growing businesses alike. Employment offices also give advice to start-ups, provide labour market training and similar career interventions for the unemployed, and offer integration training for adult immigrants. The services are mostly provided free of charge, with the exception of a few selected services for businesses.

\footnotetext{
${ }^{2}$ See Wooldridge 2010, Ch. 11.

3 TE-palvelut in Finnish.
} 


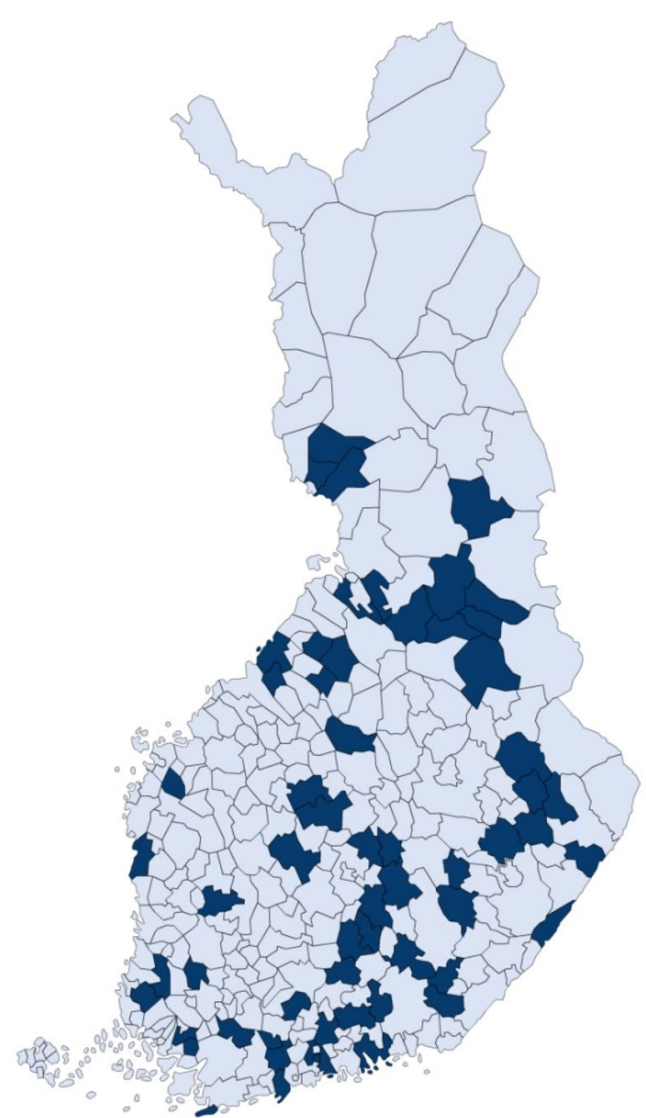

Fig. 1 Municipalities that experienced an employment office closure in the reform (in dark blue)

The Public Employment and Business Services were reformed at the beginning of the year 2013. Before the reform, the services were largely based on traditional face-to-face counselling in public employment offices. In the year 2012, there were 72 public employment offices around the country, and the offices also had branches in many smaller municipalities. After the reform, there are only 15 employment offices, with branches in selected larger cities. Out of the 311 Finnish municipalities, 61 (20\%) experienced an employment office or an office branch closure between 2012 and 2014. The aggregate employment office staff was reduced from 3,235 personyears to 2,931 person-years $(-9 \%)$ in the same period with more staff reductions being planned for the coming years. ${ }^{4}$ The locations of the affected Finnish municipalities are depicted in Fig. $1 .^{5}$

\footnotetext{
${ }^{4}$ State Budget Proposal 2014, 2016.

${ }^{5}$ We use the 2017 municipality division in our analysis. There were 311 municipalities in 2017.
}

The official goal of the reform was to expedite reemployment, ensure that public employment services meet the clients' needs, and increase the efficient use of various service channels. ${ }^{6}$ The basic premise of the reform was straightforward enough: employment offices now offer considerably less face-to-face contacts and rely more on self-service over the Internet. Also, from the year 2013 onwards, all jobseekers are divided into three categories. Category 1 clients are expected to manage largely on their own, using the Internet and email. Category 3 clients are offered most frequent contacts and face-to-face counselling with the employment office staff. Category 2 clients receive some personal counselling, but it is less intensive than in category 3.

Online counselling is largely based on self-service over the Internet. According to the Public Employment Service guidance, as a jobseeker you are able to do the following online:

- Begin your job search

- Register as an unemployed jobseeker

- Notify the employment office of any changes to your job search

- Answer questions related to the assessment of your service needs

- Draw up an employment plan together with the employment office

- Keep your contact details up to date.

Jobseekers are also encouraged to use the Public Employment Service's vacancy search engine and other similar online services to look for job advertisements. Upon close inspection, it is evident that the "counselling" part of this service is primarily related to the employment plan, which is drawn up together with the employment counsellor at the beginning of unemployment. The employment plan entails various steps that the jobseeker is supposed to do in order find re-employment, such as compiling a $\mathrm{CV}$, participating in a specific training course, taking part in rehabilitative activities, etc.

The Public Employment Service reform was planned and prepared by the Ministry of Economic Affairs and Employment during 2011-2012. The planning of the reform was based on the Ministry's report from 2010. ${ }^{7}$ This report outlined the structure of public employment services in 2015. The regional Centres for Economic Development, Transport and the Environment, which operate under the Ministry's control, aided in the planning and implementation phases of the reform. No

\footnotetext{
${ }^{6}$ Government Proposal 133/2012.

7 The Ministry of Economic Affairs and Employment (2010): The Employment Office Network in 2015 (in Finnish).
} 
municipal representatives or other interest groups took part in the planning of the reform. In the final stages of the planning phase, the affected municipalities were given the legally mandated option to state their views and opinions on the reform. These statements were merely a formality and carried little weight. The unilateral planning of the reform was later criticised by the Central Organisation of Finnish Trade Unions ${ }^{8}$ (SAK), among others. The affected municipalities also expressed their dissatisfaction. ${ }^{9}$

How to evaluate the employment effects of this reform? If a municipality's public employment office is closed, jobseekers in that municipality have to rely on telephone or email contacts with the employment administration - unless they are willing to travel to the nearest employment office, which might not be close by. In any case, they could be worse off on average than before. Some clients might be indifferent or even prefer the new situation over the obligatory visits to the employment office. But the clients who need more in-depth counselling and faceto-face communication, like category 3 clients, are literally left to their own devices.

We suggest that the employment effects of the reform might be evaluated using the following study agenda: Municipalities that had their employment office closed belong to the treatment group. Other municipalities, which did not experience a change in their employment office status, belong to the control group. We then compare the development over time in these groups. We can argue that, from the viewpoint of the inhabitants, the PES reform of 2013 is quite similar to a natural experiment in employment counselling. The affected municipalities could not affect the treatment decision in any way. As explained in detail in Sect. 3, employment office closures were targeted at smaller municipalities, but the pre-treatment unemployment rates of those municipalities did not statistically differ from those of the control municipalities.

The expected effect of this reform is ambiguous. As mentioned in the Introduction, previous literature offers contradictory evidence of the effects of both Internet job search and personal counselling. There could be more unemployment in the treated areas if face-to-face counselling is more efficient in reducing unemployment than counselling over the Internet. On the other hand, if the mode of counselling does not matter, we could also observe zero effects. This would also be interesting as online counselling requires fewer human resources and therefore generates savings in government expenditure.

\footnotetext{
${ }^{8}$ SAK Bulletin 2013 (in Finnish).

9 YLE News 8.9.2011 (in Finnish).
}

In theory, it is possible that the reform could decrease unemployment if online counselling is more efficient than personal counselling. However, this is unlikely as the clients who prefer online job search have been able to do so for some time, in addition to face-to-face counselling. As in most developed countries, Internet use is today quite prevalent in Finland. According to the yearly survey by the Statistics Finland, 92\% of population aged 16-74 had used the Internet in 2013. Approximately 50\% of population aged 16-34 had used the Internet specifically for job searches during the three months preceding the survey. ${ }^{10}$

As we mentioned earlier, the jobseekers in the affected municipalities are able to obtain face-to-face services if they are willing to travel to the nearest available PES office. The estimated effect of office closures could then be biased downwards. Therefore, we also have to account for the distance effect and the associated treatment heterogeneity. These issues are explored more closely in Sect. 5.2.

\section{Data and identification strategy}

In order to estimate the effects of the reform, we collected pre-treatment (2006-2012) and post-treatment (2013-2017) unemployment data from the treatment and control municipalities. Our data was downloaded from the open database of the Ministry of Economic Affairs and Employment of Finland. ${ }^{11}$ As the database contains monthly data, we calculated the yearly averages for each municipality from the year 2006 to the year 2017, i.e. a 12 -year panel. The reform was officially implemented at the beginning of the year 2013, but some of the affected employment offices were closed only later during that year. Therefore, in our analysis, we use the year 2014 as the first "after-the-intervention" year.

Information on public employment office locations was likewise obtained from the Ministry of Economic Affairs and Employment. Note that the treatment group only includes those municipalities that experienced an employment office closure in the PES reform. Numerous small municipalities did not have an employment office in 2012, and they are included in the control group as their situation did not change in the reform.

Aggregate time series of unemployment rates and durations before and after the reform are depicted in Fig. 2 . During 2011-2015, unemployment was continually rising due to Finland's prolonged economic recession. Note that these statistics, which we obtained from the Ministry of Economic Affairs and Employment, are not the

\footnotetext{
${ }^{10}$ Statistics Finland (2013): Use of information and communications technology by individuals.

11 From the year 2019 onwards, these data are available at https://pxnet 2.stat.fi.
} 


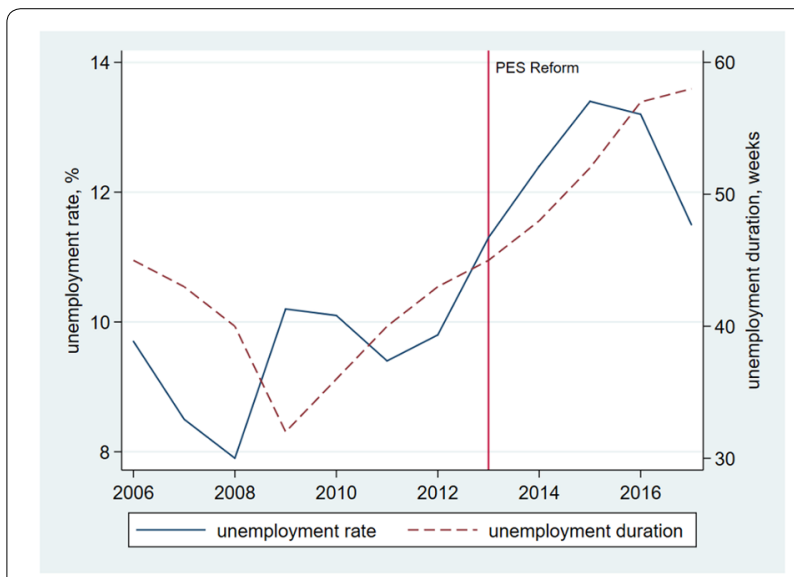

Fig. 2 Register-based unemployment rates and durations, 2006-2017

Table 1 Cross-tabulation of municipalities according to public employment services in 2012 and 2014

\begin{tabular}{lrrr}
\hline $\begin{array}{l}\text { Public employment office } \\
\text { in 2012? }\end{array}$ & \multicolumn{2}{l}{$\begin{array}{l}\text { Public employment office } \\
\text { in 2014? }\end{array}$} & Total \\
\cline { 2 - 3 } & No & Yes & \\
\hline No & 150 & 0 & 150 \\
Yes & 61 & 100 & 161 \\
Total & 211 & 100 & 311 \\
\hline
\end{tabular}

The reform was implemented in 2013

official unemployment rates. The official unemployment statistics are based on the Labour Force Survey, carried out by Statistics Finland. ${ }^{12}$ Register-based unemployment is usually several percentage points higher than the official rate.

In Table 1, municipalities are tabulated according to their employment office (or office branch) location status in 2012 and in 2014. A total of 150 municipalities did not have an employment office in 2012, prior to the treatment. A total of 61 municipalities experienced an office closure in the reform, while 100 municipalities retained their employment office. Note that, in our analysis, we equate head offices with smaller branches as both offer the possibility of face-to-face employment counselling.

Table 2 presents summary statistics on the control and treated municipalities from the pre-treatment year 2012. The share of inhabitants with tertiary education and the average age of inhabitants were almost equal. One major difference was that the treated municipalities were approximately half the size of the control municipalities: the treatment municipalities had 4,600 inhabitants in

\footnotetext{
${ }^{12}$ For reasons explained below, the official unemployment rate is not available at the municipality level.
}

workforce on average, while the control municipalities' average workforce was 9,200. Nevertheless, unemployment rates were quite similar. The control municipalities and the treated municipalities had unemployment rates of 9.7 and $10 \%$, respectively. The observed difference of $0.3 \%$ points is not statistically significant.

Interestingly, the treated municipalities had lower unemployment duration in 2012, although the difference of 2.5 weeks is not significant at the $5 \%$ level $(p=0.066)$. Note that unemployment data is missing on a number of tiny municipalities located in the Åland Islands (between Finland and Sweden) ${ }^{13}$ However, it is unlikely that this would affect our results. These municipalities did not have employment offices before the reform.

As our outcome variables, we use the unemployment rate, which is defined as 100 *unemployed/workforce, and the average duration of ongoing unemployment spells (in weeks). There is a weak positive correlation $(r=0.30)$ between the two outcome variables in the municipalitylevel data (Fig. 3).

In our data, the municipality-level unemployment rates are based on the jobseeker register, which is maintained by the Ministry of Economic Affairs and Employment. Note that these register-based figures are somewhat higher than the official unemployment statistics, which are produced by Statistics Finland based on survey data. In the monthly Labour Force Survey, 12,000 respondents are asked various questions about their employment status. A respondent is classified as "unemployed" if (1) he or she has been out of work and (2) has actively searched for a new job during the past four weeks. If the second condition is not fulfilled, the respondent is classified as being "out of workforce". Therefore, a person can be unemployed in the register (and in practice) but out of workforce in the official figures-i.e. not unemployed. Consequently, register-based unemployment rates are usually several percentage points higher than what the Labour Force Survey indicates. However, the official unemployment rates are not available at the municipality level due to the relatively small sample size of 12,000 .

According to Table 2, there are systematic pre-treatment differences between the treatment and control municipalities. In order to control for these differences, we used various panel data estimators, starting with the simplest possible, i.e. the two-period difference-indifferences estimator. ${ }^{14}$ That is, we assumed that other confounders were fixed during the treatment period under study. Taking differences then automatically controls for time-invariant variables as they drop out of the equation. Certain variables, such as the geographic size and location of the municipality, are inherently constant

\footnotetext{
${ }^{13}$ These are: Föglö, Geta, Kumlinge, Kökar, Lumparland, Sottunga, and Vårdö.

${ }^{14}$ See for instance Wooldridge (2010) for details.
} 
Table 2 Summary statistics from the year 2012, before the reform

\begin{tabular}{|c|c|c|c|c|c|c|c|c|}
\hline \multirow[t]{2}{*}{ Variable } & \multicolumn{4}{|c|}{ Control municipalities } & \multicolumn{4}{|c|}{ Treatment municipalities } \\
\hline & $\mathbf{N}$ & Mean & Min & Max & $\mathbf{N}$ & Mean & Min & Max \\
\hline Inhabitants & 250 & 19,267 & 101 & 603,968 & 61 & 10,001 & 1,450 & 37,936 \\
\hline Average age of inhabitants & 250 & 44.6 & 32.7 & 54.6 & 61 & 44.7 & 30.4 & 51.8 \\
\hline Inhabitants with tertiary education, $\%$ & 250 & 21.2 & 10 & 57 & 61 & 20.9 & 13 & 38 \\
\hline Inhabitants aged 15-64 & 250 & 12,555 & 62 & 426,402 & 61 & 6,204 & 852 & 24,901 \\
\hline Inhabitants in workforce & 250 & 9,245 & 57 & 315,455 & 61 & 4,636 & 594 & 19,113 \\
\hline Unemployed inhabitants & 243 & 944 & 9 & 24,726 & 61 & 389 & 54 & 1,206 \\
\hline Unemployment rate, \% & 243 & 9.7 & 2.0 & 20.7 & 61 & 10.0 & 4.3 & 17.4 \\
\hline Unemployment duration, weeks & 243 & 39.4 & 15.4 & 69.3 & 61 & 36.9 & 20.3 & 62.2 \\
\hline
\end{tabular}

Source: Statistics Finland, Ministry of Economic Affairs and Employment

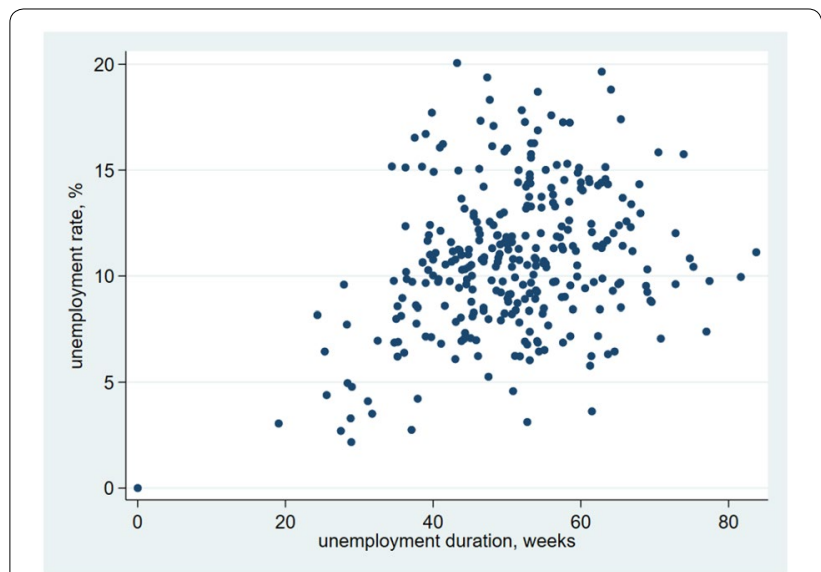

Fig. 3 Unemployment rate, \%, and average unemployment duration, weeks, in Finnish municipalities in 2017

over time. Other possible confounders, such as the demographic and business structure of the municipality, change comparatively slowly in normal circumstances, and in our baseline specification, we assumed them to be constant as well. The two-period difference-in-differences equation can therefore be written simply as:

$$
\Delta Y_{i}=\beta_{0}+\beta_{1} \text { treated }_{i}+\Delta \varepsilon_{j}
$$

The dummy variable treated equals one if the municipality was in the treatment group and zero otherwise. Delta $(\Delta)$ denotes a difference, for instance unempl rate $_{2014}-$ unempl_rate $_{2012}$, and $\varepsilon$ is the error term. Note that other confounders are included in sensitivity testing (Sect. 5).

The key identifying assumption in difference-in-differences models is that the treated units have similar trends to the control units in the absence of treatment. This assumption of parallel trends ex ante can be tested using observations from the pre-treatment periods. In this case, we used unemployment data from the years
2006-2012. Estimating Eq. 1 with pre-treatment observations should then have yielded statistically insignificant coefficients for the treatment dummy.

A somewhat more involved alternative to simple twoperiod models is the fixed effects panel data regression model, which can be written as:

$$
Y_{i t}=\beta_{0}+\beta_{1} \text { treated }_{i t} \cdot \text { year }_{t}+\beta_{t} \text { year }_{t}+v_{i}+\varepsilon_{i t}
$$

With Eq. 2, we analysed the data as a municipality panel spanning the years 2006-2017. In this case, the unobserved municipality characteristics are captured by the fixed effect $v_{i}$. To account for economy-wide fluctuations in employment we added a full set of year dummies $\left(\right.$ year $_{t}$ ), covering the time period of 2007-2017 (with 2006 as the reference year). The treatment dummy equals one for the treated municipalities during the years 2014-2017 and otherwise zero. As mentioned earlier, the reform was officially implemented on 1 January 2013, but some of the affected employment offices were closed only later in 2013. As the effect on $Y$ could vary from year to year, we interacted the treatment dummy with the year dummies.

A yet more complicated specification is to account for differing municipality-specific trends in unemployment in addition to fixed effects. Depending on various unobservable municipality factors changing over time, the unemployment trend could be decreasing or increasing. To control for this kind of heterogeneity, we first differenced Eq. 2 to remove the fixed effect and then applied the standard FE estimator to the differenced equation.

$$
\Delta Y_{i t}=\beta_{0}+\beta_{1} \Delta \text { treated }_{i t} \cdot \text { year }_{t}+\beta_{t} \text { year }_{t}+v_{i}+\Delta \varepsilon_{i t}
$$

In Eq. 3, the term $v_{i}$ captures the municipality-specific trends. Our estimation strategy therefore started with the simplest possible model and progressed towards more complicated estimators, which also allowed us to compare the results of different models. 
Table 3 The effects of the 2013 PES reform: difference-in-differences regression coefficients, baseline specification

\begin{tabular}{llc}
\hline & (1) Dependent variable: unemployment rate (\%) & $\begin{array}{l}\text { (2) Dependent variable: } \\
\text { unemployment duration } \\
\text { (weeks) }\end{array}$ \\
\hline Panel A: pre-treatment time periods & & $-0.141(0.849)$ \\
2006-2008 & & $0.502(1.041)$ \\
2006-2009 & $-0.076(0.159)$ & $0.617(1.026)$ \\
2006-2010 & $-0.146(0.232)$ & $0.268(1.003)$ \\
2006-2011 & $-0.274(0.293)$ & $-0.069(1.060)$ \\
2006-2012 & $-0.408(0.326)$ & $1.191(0.647)$ \\
Panel B: post-treatment time periods & $-0.277(0.336)$ & $2.318^{* *}(0.846)$ \\
2012-2014 & & $3.184^{* *}(1.087)$ \\
2012-2015 & $0.534^{*}(0.269)$ & $2.628^{*}(1.153)$ \\
2012-2016 & $0.515^{*}(0.239)$ & $0.296(0.228)$ \\
2012-2017 & $0.303(0.239)$ & \\
\hline
\end{tabular}

The entries are coefficients $\beta_{1}$ in the equation $\Delta Y_{i}=\beta_{0}+\beta_{1}$ treated $_{i}+\Delta \varepsilon_{i}$. All equations were estimated using two years of data, i.e. the first and the last year of each period. $\mathrm{N}=303-304$. Heteroscedasticity-robust standard errors in parentheses. Statistical significance is denoted as: ${ }^{*} \mathrm{p} \leq 0.05 ;{ }^{* *} \mathrm{p} \leq 0.01$; ${ }^{* * *} \mathrm{p} \leq 0.001$

Table 4 The effects of the 2013 PES reform: fixed effects panel data regression coefficients

\begin{tabular}{|c|c|c|c|c|}
\hline Independent variable & $\begin{array}{l}\text { (1) Dependent variable: } \\
\text { unemployment rate (\%) }\end{array}$ & $\begin{array}{l}\text { (2) Dependent variable: } \\
\text { unemployment duration } \\
\text { (weeks) }\end{array}$ & $\begin{array}{l}\text { (3) Dependent } \\
\text { variable: difference } \\
\text { in unemployment rate (\%) }\end{array}$ & $\begin{array}{l}\text { (4) Dependent variable: } \\
\text { difference in unemployment } \\
\text { duration (weeks) }\end{array}$ \\
\hline Year 2007 & $-1.306^{* * *}(0.048)$ & $-1.540^{* * *}(0.239)$ & - & - \\
\hline Year 2008 & $-1.758^{* * *}(0.064)$ & $-4.382^{* * *}(0.357)$ & $0.854^{* * *}(0.060)$ & $-1.302^{* * *}(0.300)$ \\
\hline Year 2009 & $0.617^{* * *}(0.082)$ & $-11.618^{* * *}(0.456)$ & $3.689^{* * *}(0.082)$ & $-5.678^{* * *}(0.438)$ \\
\hline Year 2010 & $0.093(0.099)$ & $-8.872^{* * *}(0.492)$ & $0.789^{* * *}(0.067)$ & $4.330^{* * *}(0.316)$ \\
\hline Year 2011 & $-0.661^{* * *}(0.102)$ & $-5.151^{* * *}(0.512)$ & $0.552^{* * *}(0.067)$ & $5.271^{* * *}(0.308)$ \\
\hline Year 2012 & $-0.346^{* * *}(0.104)$ & $-1.994^{* * *}(0.550)$ & $1.625^{* * *}(0.062)$ & $4.667^{* * *}(0.322)$ \\
\hline Year 2013 & $0.913^{* * *}(0.101)$ & $-0.578(0.572)$ & $2.567^{* * *}(0.077)$ & $2.915^{* * *}(0.329)$ \\
\hline Year 2014 & $1.906^{* * *}(0.110)$ & $2.557^{* * *}(0.649)$ & $2.311^{* * *}(0.078)$ & $4.712^{* * *}(0.345)$ \\
\hline Year 2015 & $2.688^{* * *}(0.115)$ & $5.441^{* * *}(0.646)$ & $2.091^{* * *}(0.066)$ & $4.431^{* * *}(0.352)$ \\
\hline Year 2016 & $2.307^{* * *}(0.119)$ & $8.785^{* * *}(0.697)$ & $0.926^{* * *}(0.065)$ & $5.007^{* * *}(0.400)$ \\
\hline Year 2017 & $0.765^{* * *}(0.117)$ & $9.624^{* * *}(0.701)$ & $-0.244^{* * *}(0.069)$ & $2.407 * * *(0.396)$ \\
\hline Year 2014 × reform & $0.413^{*}(0.205)$ & $0.959(0.726)$ & $0.366(0.193)$ & $0.816(0.468)$ \\
\hline Year $2015 \times$ reform & $0.400(0.215)$ & $2.077^{*}(0.862)$ & $0.363(0.209)$ & $1.902^{*}(0.837)$ \\
\hline Year 2016 × reform & $0.181(0.203)$ & $2.990^{* *}(1.095)$ & $0.155(0.231)$ & $2.668^{*}(1.172)$ \\
\hline Year $2017 \times$ reform & $0.171(0.193)$ & $2.471 *(1.104)$ & $0.168(0.288)$ & $2.097(1.337)$ \\
\hline Constant & $10.042^{* * *}(0.073)$ & $40.794^{* * *}(0.402)$ & $-1.307^{* * *}(0.043)$ & $-1.544^{* * *}(0.230)$ \\
\hline Municipality fixed effects & Yes & Yes & Yes & Yes \\
\hline Municipality-specific trends & No & No & Yes & Yes \\
\hline N & 3,657 & 3,657 & 3,344 & 3,344 \\
\hline R-sq & 0.652 & 0.599 & 0.646 & 0.416 \\
\hline
\end{tabular}

Municipality-clustered standard errors in parentheses. Interaction terms year-reform are differenced in models 3 and 4 . Statistical significance is denoted as: * $p \leq 0.05$; ** $p \leq 0.01 ;{ }^{* * *} p \leq 0.001$

\section{Results}

In this section we present our main results from the difference-in-differences regressions (Table 3) and the fixed effects regressions (Table 4). Our outcome variables are the municipal unemployment rate and the average unemployment duration. First, we tested for the existence of parallel trends before the treatment, which is a necessary requirement for the difference-in-differences estimator to produce valid results. If trends are diverging prior to the intervention, we do not have credible counterfactual (Meyer 1995). As our pre-treatment time periods, we used the years 2006-2008, 2006-2009, 2006-2010, 
2006-2011, and 2006-2012; the reform was implemented during 2013. As our post-treatment time periods, we used the years 2012-2014, 2012-2015, 2012-2016, and 2012-2017. That is, we took the year immediately prior to the reform, 2012, and a single year after the reform, and compared the differences in the changes.

Table 3 presents the results from our baseline specification, where the sole independent variable was the treatment dummy. First, we examined the pre-treatment time periods (Table 3, Panel A). We found no statistically significant differences in the unemployment rate or duration changes between the treatment and control municipalities in the time periods before the treatment, i.e. the year 2013. We conclude that the control and the treatment municipalities had parallel pre-treatment trends.

Note that, in Table 3, we use two-period differencein-differences models throughout. For the first pretreatment regression, we use data from the years 2006 and 2008 and take a two-year difference, i.e. unempl_ rate $_{2008}-$ unempl_rate 2006 . Similarly, for the post-treatment period 2012-2015, we use a three-year difference, unempl_rate ${ }_{2015}-$ unempl_rate ${ }_{2012}$, etc.

The employment office reform was implemented during the year 2013; some of the affected offices were closed in late 2013. After the intervention, i.e. from year 2015 onwards, we found statistically significant differences in the changes of average unemployment durations at the 5\% level (Table 3, Panel B). Note that, for the 2012-2014 period, the $p$-value of the treatment dummy is 0.066 .

In the treated municipalities, the average unemployment duration increased by 1.2-3.2 weeks compared with the control municipalities, depending on the time period in question. The largest effect is detected in 2012-2016: the increase in average unemployment duration in the treated municipalities was 3.2 weeks larger than in the control municipalities. Recall from Fig. 1 that unemployment durations have been continually on the rise in Finland after 2009. Prior to the reform, the average unemployment duration in the treated municipalities was 37 weeks (Table 2).

We also find significant coefficients for the treatment dummy in the unemployment rate equation for the time periods 2012-2014 and 2012-2015. However, later time periods do not produce similar findings. Note that the mode of employment counselling is not the root cause of unemployment, which depends on economic fluctuations. However, counselling modality can affect the length of unemployment spells: efficient counselling can shorten the period of unemployment, but inefficient counselling may have opposite effects. According to our results shown in Table 3, relying on online and telephone counselling has had an adverse effect on unemployment durations in the treated municipalities. Therefore, it seems that traditional face-to-face counselling is more efficient than online counselling in reducing unemployment duration. However, counselling modality does not have a significant effect on the unemployment rate. As depicted in Fig. 3, correlation between the unemployment rate and the average duration is weak.

In 2015, there were some 33,000 unemployed inhabitants in the treated municipalities. According to the report by the National Audit Office of Finland, ${ }^{15}$ employment office clients are divided roughly equally to the three different client categories (1-3), and the clients in category 3 need most attention and face-to-face counselling. However, as this information is quite sensitive, municipality-level data on client categories are not publicly available. Therefore, we can only obtain a rough estimate of the number of jobseekers, approximately 11,000, who suffered the most from the reform.

By way of comparison to simple two-period differencein-differences estimators, we also analysed the data as a multi-year municipality panel. We present the estimates from the fixed effects panel data regression (Eq. 2) in Table 4, columns 1 and 2. In Table 4, the year dummies 2007-2017 control for the economy-wide fluctuations that affect the unemployment rate and duration. The fixed effects $v_{i}$ control for the time-invariant municipality-level characteristics, such as the municipality's location and size. The interaction terms year.reform measure the effect of the 2013 PES reform, by year. Not surprisingly, the coefficient estimates are similar to those in Table 3, Panel B. Unemployment durations increased by 2-3 weeks in the treated municipalities.

An even more refined specification is to add municipality-specific unemployment trends, which is accomplished by first differencing Eq. 2 and then estimating the model using fixed effects regression (Eq. 3). In this case, we control for both the unobserved time-invariant factors (by taking differences) and the unobserved factors that change over time and cause a gradual change in the municipalities' unemployment rate and duration-for instance, a slow migration from rural areas to larger cities. ${ }^{16}$ We present the results in Table 4 , columns 3 and 4.

For the unemployment rate changes, we do not observe significant coefficients at the $5 \%$ level. The interactions of the reform and years 2014 and 2015 have $p$-values of 0.059 and 0.083 , respectively. For the unemployment duration changes, we find significant coefficients at the $5 \%$ level for the reform when interacted with the years 2015 and 2016. The coefficient $p$-values for the years 2014 and 2017 are 0.083 and 0.118 , respectively. Hence,

\footnotetext{
${ }^{15}$ National Audit Office of Finland (2015): Digital employment services (in Finnish).

16 This specification is sometimes called the random trend model. See Wooldridge (2010), Chapter 11.7.
} 


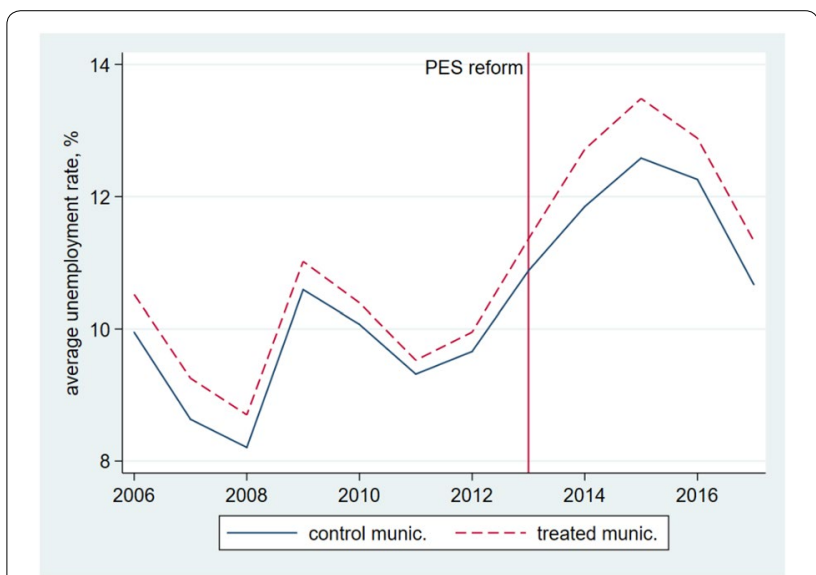

Fig. 4 Average unemployment rates in control and treatment municipalities, 2006-2017

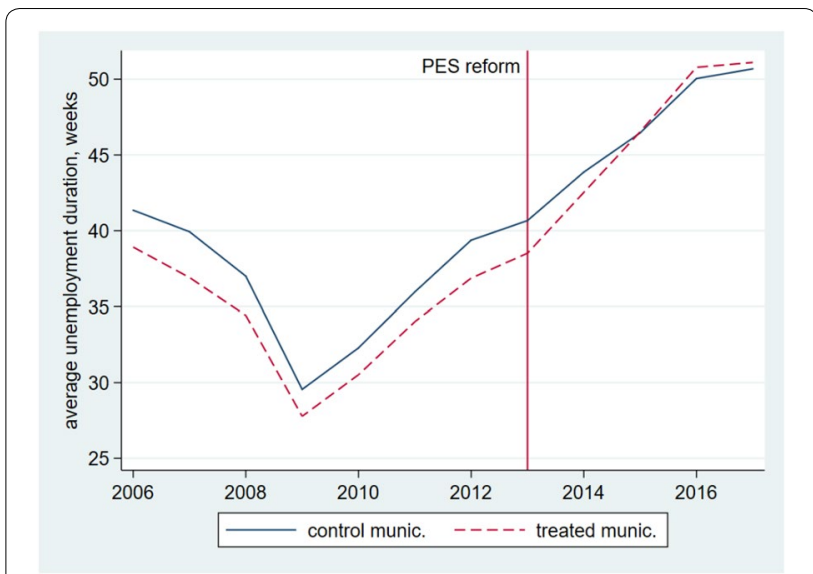

Fig. 5 Average unemployment durations in control and treatment municipalities, 2006-2017

we find similar effects as in Table 3, Panel B, although the coefficients are somewhat smaller. However, the overall result remains the same: the reform increased unemployment duration by $2-3$ weeks in $2015-2016$, and it had a small-statistically indiscernible-effect on the unemployment rate as well.

Figures 4 and 5 illustrate the data behind our findings. In Fig. 4, we depict the time series of the average unemployment rates in the control and treatment municipalities from 2006 to 2017. Before the treatment, the trends were very similar. After the 2013 reform, we observe a slight increase in the treated municipalities' unemployment compared with that of the control municipalities. However, the effect subsides quickly.

In Fig. 5, we depict the average unemployment durations in the control and treated municipalities from 2006 to 2017. In this case, we observe a visible change in the treated municipalities' unemployment duration after the reform when compared with the control municipalities. Before the 2013 reform, the treated municipalities had an average unemployment duration consistently below the average unemployment duration of the control municipalities. The reform gradually reversed the order.

As mentioned earlier, the estimates in Tables 3 and 4 might be biased downwards, since some unemployed jobseekers in the affected municipalities could have travelled to a municipality with an existing PES office to obtain face-to-face counselling. This extra workload could also have influenced the productivity of the counsellors in those PES offices. Unfortunately, there are no data on such non-local counselling appointments available as jobseeker clients are able to choose any PES office for their service needs. However, in Sect. 5.2 we explore the effect of distance-specifically, driving times-on our baseline estimates.

\section{Sensitivity testing}

\subsection{Confounding variables}

As always, finding a statistically significant regression coefficient for the treatment is not enough to warrant any definite statements about the causal effect. In order to verify the robustness of our main results in Table 3, we carried out a multitude of various sensitivity tests. There are a number of possible confounders and complications that have to be accounted for, and the results are presented in this Section. We will first describe the possible confounders one by one and then present the augmented difference-in-differences equations for the unemployment rate and the unemployment duration.

\section{Lapland region}

From the map of Finland in Fig. 1, we observe that the PES offices that were closed in the 2013 reform were scattered fairly evenly across the country-except for Lapland, the northernmost part of Finland. Only three of the closed PES offices were located in Lapland, ${ }^{17}$ although it is by far the largest region geographically. Lapland is a special region in various ways. It is very sparsely populated, with a population density of 1.9 inhabitants $/ \mathrm{km}^{2}$. The average population density in Finland is 16.3 inhabitants $/ \mathrm{km}^{2}$, which is still quite low compared with most European countries. In Lapland, unemployment has traditionally been higher than average: in 2012, prior to the PES reform, the register-based unemployment rate was $13.4 \%$ in Lapland and $9.6 \%$ in the other regions. Consequently, Lapland often receives special treatment in regional policy. Hence, we include a Lapland region dummy in our equations. ${ }^{18}$

\footnotetext{
${ }^{17}$ In the municipalities of Keminmaa, Simo, and Tervola.

18 Note that as location is time-invariant, it drops out when we take differences. In this case, we can interpret the Lapland dummy as describing a special treatment for Lapland, starting from 2013.
} 
Table 5 The effects of the 2013 PES reform: difference-in-differences regression coefficients, alternative specifications (dependent variable: unemployment rate)

\begin{tabular}{|c|c|c|c|c|}
\hline Independent variable & $\begin{array}{l}\text { (1) Time period } \\
2012-2014\end{array}$ & $\begin{array}{l}\text { (2) Time period } \\
2012-2015\end{array}$ & $\begin{array}{l}\text { (3) Time period } \\
2012-2016\end{array}$ & $\begin{array}{l}\text { (4) Time } \\
\text { period } \\
2012-2017\end{array}$ \\
\hline Treated municipality & $0.556^{*}(0.269)$ & $0.372(0.204)$ & $0.349(0.236)$ & $0.310(0.246)$ \\
\hline Lapland region & $1.086^{* * *}(0.294)$ & $0.442(0.255)$ & $-0.358(0.357)$ & $-0.557(0.303)$ \\
\hline Long-term unemployed pilot project in 2012-2015 & $-0.106(0.165)$ & $-0.076(0.172)$ & $0.151(0.191)$ & $0.159(0.205)$ \\
\hline Recipient of mass layoff support in 2013-15 & $-0.029(0.233)$ & $0.236(0.223)$ & & \\
\hline Recipient of mass layoff support in 2015 & & $2.249(1.264)$ & & \\
\hline Recipient of mass layoff support in 2016-17 & & & $0.083(0.421)$ & $-0.566^{*}(0.241)$ \\
\hline PES office closure in 2016-17 & & & $0.441(0.282)$ & $-0.072(0.211)$ \\
\hline Constant & $2.175^{* * *}(0.101)$ & $2.956^{* * *}(0.108)$ & $2.576^{* * *}(0.110)$ & $1.106^{* * *}(0.110)$ \\
\hline N & 303 & 303 & 304 & 304 \\
\hline R-sq & 0.058 & 0.074 & 0.019 & 0.023 \\
\hline
\end{tabular}

Dependent variable: unemployment rate (\%)

All equations are estimated with two years of data, i.e. the first and the last year of each period. Heteroscedasticity-robust standard errors in parentheses. Statistical significance is denoted as: ${ }^{*} p \leq 0.05 ;{ }^{* *} p \leq 0.01 ;{ }^{* *} p \leq 0.001$

Pilot project on the long-term unemployed (2012-2015)

During the years 2012-2015, the Ministry of Economic Affairs and Employment financed a pilot project where selected municipalities $(\mathrm{N}=59$ current municipalities) officially started to implement their own policies and interventions for the long-term unemployed. The objective of the pilot project was to innovate and establish new treatments for the then-growing problem of long-term unemployment. As the pilot project could have affected the unemployment rates and durations, we should control for the pilot project municipalities in our differencein-difference equations. Therefore, we include a pilot project dummy in our models. Since the objective was to create permanent systems, we also include the pilot dummy in the later time periods $(2016,2017)$.

Special support for mass layoff areas

Since the year 2007, the Government has supported sub-regions and single municipalities that have experienced an unexpected, large employment shock, for instance the sudden closure of a paper mill or a large factory. Officially named "Government support for areas of abrupt structural change", these support measures have been transitory (for 1-3 years after the event), and their objective has been to create new entrepreneurship in the affected areas. As the mass layoffs or the corresponding support measures could have had an effect on unemployment, we include mass layoff dummies for the corresponding time periods in our models.

Later PES Office closures

The 2013 PES reform was not the end of Public Employment Services' reorganisation. Further PES office closures followed during 2016-2017, and these events may have contributed to the unemployment rates and durations in the affected municipalities, causing bias to our baseline estimates. In order to account for these changes, we control for these municipalities in our modified unemployment rate and duration equations with a dummy variable.

We present our difference-in-differences regression estimates with additional dummy variables in Tables 5 and 6, where the dependent variables are the unemployment rate and the unemployment duration, respectively. The four post-treatment time periods are presented in columns $1-4$, and the independent variables are in rows, with the treatment dummy in the first row.

The sensitivity tests in Tables 5 and 6 do not change our overall conclusions. Except for the Lapland dummy and the mass layoff support dummy in 2016-17, other confounders are not even statistically significant. As mass layoff support could also have long-term effects, we also performed sensitivity test regressions for 2012-2016 and 2012-2017 with layoff support dummies for 20132015. ${ }^{19}$ Also in this case, the dummies are insignificant, and the overall results remain the same.

Hence, our baseline results from Table 3 are quite robust to various confounder specifications. However, this finding does not preclude the existence of other external factors that may have affected our outcome variables in tandem with the treatment. For the time being, we merely state that we were unable to find such a factor.

\subsection{Treatment heterogeneity}

Up to this point, we have assumed that the treatmentthe closure of the PES office-has affected the treated municipalities' PES office clients in a homogenous way.

\footnotetext{
${ }^{19}$ Results are available on request.
} 
Table 6 The effects of the 2013 PES reform: difference-in-differences regression coefficients, alternative specifications (dependent variable: unemployment duration)

\begin{tabular}{lllll}
\hline Independent variable & $\begin{array}{l}\text { (1) Time period } \\
\text { 2012-2014 }\end{array}$ & $\begin{array}{l}\text { (2) Time period } \\
\text { 2012-2015 }\end{array}$ & (3) Time period 2012-2016 & (4) Time period 2012-2017 \\
\hline Treated municipality & $1.236(0.646)$ & $2.264^{* *}(0.851)$ & $3.221^{* *}(1.110)$ & $2.494^{*}(1.193)$ \\
Lapland region & $5.631^{* * *}(0.970)$ & $6.230^{* * *}(1.050)$ & $5.693^{* * *}(1.457)$ & $3.690^{* *}(1.348)$ \\
Long-term unemployed pilot project in 2012-2015 & $-0.792(0.655)$ & $-1.155(0.835)$ & $-1.228(1.094)$ & $-1.508(1.194)$ \\
Recipient of mass layoff support in 2013-15 & $0.425(0.949)$ & $0.093(1.023)$ & & $3.888(2.107)$ \\
Recipient of mass layoff support in 2015 & & $1.950(2.212)$ & & $0.033(1.376)$ \\
Recipient of mass layoff support in 2016-17 & & & $1.984(2.653)$ & $11.568^{* * *}(0.742)$ \\
PES office closure in 2016-17 & & & $0.401(1.368)$ & 304 \\
Constant & $4.164^{* * *}(0.440)$ & $7.093^{* * *}(0.518)$ & $10.478^{* * *}(0.691)$ & 0.037 \\
N & 303 & 303 & 304 & 0.060 \\
R-sq & 0.082 & 0.090 & &
\end{tabular}

Dependent variable: unemployment duration (weeks)

All equations are estimated with two years of data, i.e. the first and the last year of each period. Heteroscedasticity-robust standard errors in parentheses. Statistical significance is denoted as: ${ }^{*} \mathrm{p} \leq 0.05 ;{ }^{* *} \mathrm{p} \leq 0.01 ;{ }^{* * *} \mathrm{p} \leq 0.001$

However, treatment intensity could well depend on the distance to the nearest municipality with an existing PES office. The unemployed in need of face-to-face counselling are worse off if the distance is large, and vice versa. Hence, the treatment effects might be heterogeneous. In order to test for the treatment heterogeneity, we collected information on the distances-or more specifically, driving times using a private car-between the affected municipalities and the nearest municipality with an existing PES office. ${ }^{20}$

The distribution of driving times is depicted in Fig. 6. The mean driving time is $31 \mathrm{~min}$ using a private car. Note that when using public transport, the travel times could easily be two- or three-fold, or even longer. It is unlikely that all unemployed persons have a private car at their disposal. Unfortunately, we do not have data available on public transport travelling times between Finnish municipalities. Therefore, we should consider these driving times as the lower bound of the true travelling times.

To test for treatment heterogeneity, we divide the treatment municipalities into three groups: municipalities with a drivetime of less than $20 \mathrm{~min}$, municipalities with a drivetime of $20-40 \mathrm{~min}$, and municipalities with a drivetime of more than $40 \mathrm{~min}$ to the nearest PES office municipality. These groups are depicted in Fig. 6 with vertical dash lines. Using the panel data from 2006-2017, we obtain the following number of treated observations (years 2014-2017) per group:
- reform-near $(<20 \mathrm{~min}) \mathrm{N}=36$

- reform-mean (20-40 min) $\mathrm{N}=164$

- reform-far (>40 min) $\mathrm{N}=44$.

We then assign a separate treatment dummy to each of these groups and include these dummy variables-interacted with the year dummies-in the panel data regressions. The results are presented in Table 7 .

In Table 7, we find that although some of the coefficients are large in magnitude, they are not statistically significant at the $5 \%$ level. In the unemployment duration equations, only the interaction terms of the farthest distance municipalities are significant at the 1 or $5 \%$ level. To summarise the results, we can also test the joint significance of the interaction terms in each distance category with the $F$-test. These test statistics are presented in Table 8.

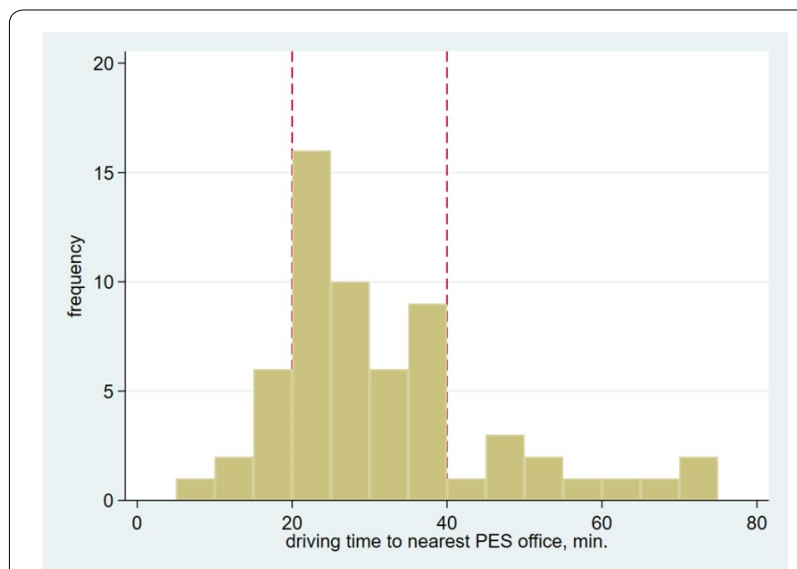

Fig. 6 Driving time from the affected municipalities to the nearest municipality with a PES office 
Table 7 The effects of the PES reform: fixed effects panel data regression estimates, treatment groups by driving time to the nearest PES office

\begin{tabular}{|c|c|c|c|c|}
\hline Independent variable & $\begin{array}{l}\text { (1) Dependent variable: } \\
\text { unemployment rate (\%) }\end{array}$ & $\begin{array}{l}\text { (2) Dependent variable: } \\
\text { unemployment duration } \\
\text { (weeks) }\end{array}$ & $\begin{array}{l}\text { (3) Dependent } \\
\text { variable: difference } \\
\text { in unemployment rate }(\%)\end{array}$ & $\begin{array}{l}\text { (4) Dependent variable: } \\
\text { difference in unemployment } \\
\text { duration (weeks) }\end{array}$ \\
\hline Year $2014 \times$ ref-near & $0.195(0.290)$ & $1.367(0.898)$ & $-0.073(0.150)$ & $1.058(0.901)$ \\
\hline Year $2015 \times$ ref-near & $0.181(0.328)$ & $2.130(1.412)$ & $-0.171(0.250)$ & $1.652(1.302)$ \\
\hline Year 2016 × ref-near & $0.293(0.408)$ & $3.712(2.294)$ & $-0.142(0.336)$ & $2.950(2.426)$ \\
\hline Year 2017 × ref-near & $0.566(0.366)$ & $4.390(2.418)$ & $0.059(0.390)$ & $3.439(2.676)$ \\
\hline Year $2014 \times$ ref-mean & $0.578^{*}(0.248)$ & $0.642(0.862)$ & $0.506(0.270)$ & $0.709(0.578)$ \\
\hline Year $2015 \times$ ref-mean & $0.461(0.236)$ & $1.736(1.061)$ & $0.394(0.268)$ & $1.840(1.096)$ \\
\hline Year 2016 × ref-mean & $0.237(0.216)$ & $2.322(1.362)$ & $0.176(0.308)$ & $2.347(1.452)$ \\
\hline Year $2017 \times$ ref-mean & $0.221(0.209)$ & $2.006(1.372)$ & $0.177(0.387)$ & $2.048(1.674)$ \\
\hline Year 2014 × ref-far & $-0.023(0.498)$ & $1.807(1.574)$ & $0.204(0.217)$ & $1.015(0.736)$ \\
\hline Year $2015 \times$ ref-far & $0.353(0.682)$ & $3.303^{*}(1.643)$ & $0.687(0.424)$ & $2.336^{*}(1.028)$ \\
\hline Year $2016 \times$ ref-far & $-0.122(0.617)$ & $4.891^{* *}(1.671)$ & $0.319(0.304)$ & $3.633^{*}(1.546)$ \\
\hline Year $2017 \times$ ref-far & $-0.336(0.556)$ & $2.635(1.583)$ & $0.224(0.394)$ & $1.182(1.619)$ \\
\hline Constant & $10.042^{* * *}(0.073)$ & $40.794^{* * *}(0.403)$ & $-1.307^{* * *}(0.043)$ & $-1.544^{* * *}(0.231)$ \\
\hline Year indicators & Yes & Yes & Yes & Yes \\
\hline Municipality fixed effects & Yes & Yes & Yes & Yes \\
\hline Municipality-specific trends & No & No & Yes & Yes \\
\hline N & 3,657 & 3,657 & 3,344 & 3,344 \\
\hline R-sq & 0.653 & 0.600 & 0.647 & 0.417 \\
\hline
\end{tabular}

Municipality-clustered standard errors in parentheses. Interaction terms year.reform are differenced in models 3 and 4 . Statistical significance is denoted as: * $p \leq 0.05$; ${ }^{* *} \mathrm{p} \leq 0.01 ;{ }^{* * *} \mathrm{p} \leq 0.001$

Table 8 Joint significance tests of the reform·year interaction terms, by distance category

\begin{tabular}{llllr}
\hline Treatment group & (1) Unemployment rate & $\begin{array}{l}\text { (2) Unemployment } \\
\text { duration }\end{array}$ & (3) $\Delta$ unemployment rate & $\begin{array}{l}\text { (4) } \\
\Delta \text { unemployment } \\
\text { duration }\end{array}$ \\
\hline Reform-near & $F=2.14(0.075)$ & $F=1.20(0.311)$ & $F=0.72(0.582)$ & $F=0.55(0.701)$ \\
Reform-mean & $F=1.58(0.179)$ & $F=0.97(0.424)$ & $F=1.64(0.165)$ & $F=0.79(0.530)$ \\
Reform-far & $F=0.81(0.517)$ & $F=3.04(0.018)$ & $F=0.86(0.485)$ & $F=3.08(0.017)$ \\
\hline
\end{tabular}

$p$ values in parentheses. Statistically significant test statistics in italics type

Joint significance tests confirm our findings from Table 7: exclusively those municipalities which are located the farthest from an existing PES office yield statistically significant coefficients. Therefore, we conclude that in the affected municipalities, distance to proper PES services makes a difference. The longer it takes for the unemployed jobseeker to reach face-to-face counselling service, the larger the increase in unemployment duration because of the PES reform.

\section{Conclusions}

In Finland, the Public Employment Service reform of 2013 transferred a large part of employment counselling services from face-to-face contacts to online counselling. Several dozen smaller municipalities experienced an involuntary employment office closure, and from the year 2013 onwards their unemployed inhabitants have been expected to manage on their own, using the public employment services on the Internet or by telephoneunless they are willing to travel to the nearest PES office. While the reform might produce some cost savings due to reduced staff costs, it could also yield negative outcomes. Labour markets are unlike ordinary goods markets, and many jobseekers, especially newcomers, often need indepth counselling in order to find suitable employment or further training. It is not necessarily straightforward to substitute traditional face-to-face employment counselling with other modes of counselling. The reform created circumstances that allow us to study the aggregate effects of face-to-face counselling on labour market outcomes 
at the municipality level and whether it is possible to replace face-to-face counselling with online counselling.

We studied the effects of the reform using municipality-level panel data and various panel data estimators. Our results suggest that while the reform had only minor effect on unemployment rates, it caused an increase of 2-3 weeks in average unemployment durations in the treated municipalities. Counselling modality is not the root cause of unemployment, which mainly depends on economic fluctuations. However, the mode of counselling could affect the duration of unemployment; effective counselling may decrease the duration and vice versa. Based on our regression estimates, online counselling is not as effective in reducing unemployment duration as traditional face-to-face counselling. Our baseline estimates are robust to various sensitivity checks. We also find that distance to proper counselling services is a contributing factor: the longer the driving time to the nearest PES office, the larger the increase in unemployment duration in the affected municipalities.

A back-of-the-envelope calculation of the fiscal costs and benefits of the reform reveals that the fiscal costs of the reform could outweigh the fiscal benefits by a large margin. Due to the increased unemployment duration, the total of additional unemployment allowances, housing benefits, and social assistance is approximately 24 million euros. On the other hand, the savings in employment counsellors' salary costs (including social security contributions) and office rents total approximately 12 million euros. ${ }^{21}$

The PES reform was unilaterally planned by the Ministry of Economic Affairs and Employment, without any involvement from municipalities or other interest groups. As mentioned above, the unilateral planning of the reform was criticized by the Trade Unions and the affected municipalities. In hindsight, these criticisms were justified from the viewpoint of workers and unemployed inhabitants. Future PES reforms should engage relevant interest groups in order to mitigate the possible negative effects of the reforms.

Nevertheless, the one-sided implementation of the reform created good circumstances for impact evaluation. Our study agenda closely resembles a natural experiment, where some municipalities, picked out in a random-like fashion, experience an involuntary employment office closure. Before the reform, the unemployment rates of the treated municipalities were not statistically different from those of the non-treated municipalities. The major difference was that the treated

\footnotetext{
${ }^{21}$ Sources: Statistics Finland; the Social Insurance Institution of Finland (Kela); the National Institute of Health and Welfare (THL). Details available on request.
}

municipalities were considerably smaller in population. Our results suggest that while service replacement is technically possible, the outcomes are not necessarily the same. There is no substitute for the human touch.

Future research should deepen our understanding of the effectiveness of various PES service channels, that is, the effects of using the Internet services, or e-mail, or telephone, or face-to-face counselling. The exogenous changes of the year 2013 reform could be a useful starting point. This exercise would require detailed client-level data on the use of different service channels before and after the 2013 reform. Combining the PES Offices' client registers and the high-quality registers of Statistics Finland could yield relevant data for a more detailed service channel evaluation.

\section{Acknowledgements}

Not applicable.

\section{Authors' contributions}

The author read and approved the final manuscript.

\section{Funding}

This study has not received external funding.

\section{Availability of data and materials}

The datasets used and analysed during the current study are available from the corresponding author on reasonable request.

\section{Competing interests}

The author declares that he has no competing interests.

Received: 11 November 2019 Accepted: 4 August 2020

Published online: 28 August 2020

\section{References}

Behncke, S., Frölich, M., Lechner, M.: A caseworker like me-does the similarity between the unemployed and their caseworkers increase job placements? Econ. J. 120, 1430-1459 (2010a)

Behncke, S., Frölich, M., Lechner, M.: Unemployed and their caseworkers: should they be friends or foes? J. R. Stat. Soc. Ser. A. 173, 67-92 (2010b)

Breunig, R., Cobb-Clark, D.A., Dunlop, Y., Terrill, M.: Assisting the long-term unemployed: results from a randomised trial. Econ. Record. 79, 84-102 (2003)

Brown, S.D., Roche, M.: The outcomes of vocational interventions: thirty (some) years later. J. Career. Assess. 24, 26-41 (2016)

Crépon, B., Dejemeppe, M., Gurgand M.: Counseling the unemployed: does it lower unemployment duration and recurrence? Institute for the Study of Labor, Discussion Paper 1796 (2005)

Huber, M., Lechner, M., Mellace, G.: Why do tougher caseworkers increase employment? The role of program assignment as a causal mechanism. Rev. Econ. Stat. 99, 180-183 (2017)

Kroft, K., Pope, D.G.: Does online search crowd out traditional search and improve matching efficiency? Evidence from craigslist. J. Labor. Econ. 32, 259-303 (2014)

Kuhn, P., Mansour, H.: Is internet job search still ineffective? Econ. J. 124, 1213-1233 (2014)

Kuhn, P., Skuterud, M.: Internet job search and unemployment durations. Am. Econ. Rev. 94, 218-232 (2004)

Meyer, B.: Natural and quasi-experiments in economics. J. Bus. Econ. Stat. 13 151-161 (1995)

Schiprowski, A.: The role of caseworkers in unemployment insurance: evidence from unplanned absences. IZA, Paris, Discussion Papers, No. 11040 (2017) 
Stevenson, B.: The internet and job search. National Bureau of Economic Research, Cambridge, Working paper 13886 (2008)

Van den Berg, G.J., Van der Klaauw, B.: Counseling and monitoring of unemployed workers: theory and evidence from a controlled social experiment. Int. Econ. Rev. 47, 895-936 (2006)

Whiston, S.C., Brecheisen, B.K., Stephens, J.: Does treatment modality affect career counseling effectiveness? J. Vocat. Behav. 62, 390-410 (2003)
Wooldridge, J.M.: Econometric analysis of cross section and panel data, 2nd edn. MIT Press, Cambridge (2010)

\section{Publisher's Note}

Springer Nature remains neutral with regard to jurisdictional claims in published maps and institutional affiliations.
Submit your manuscript to a SpringerOpen ${ }^{0}$ journal and benefit from:

- Convenient online submission

- Rigorous peer review

- Open access: articles freely available online

- High visibility within the field

- Retaining the copyright to your article

Submit your next manuscript at $\boldsymbol{\nabla}$ springeropen.com 